\title{
The Investigation on Flexural Toughness of Partially Steel Fiber Reinforced Concrete Immersed by Simulated Sea-Water
}

\author{
Feng GAO ${ }^{1 *}$, Yujun GUO ${ }^{2}$, Hui YUAN ${ }^{3}$, Chunlei FAN ${ }^{4}, \mathrm{Ke} \mathrm{LI}^{5}$ \\ ${ }^{1}$ School of Civil Engineering and Architecture, University of Jinan, Jinan250022, Shandong, China \\ ${ }^{2}$ Department of housing and Urban-Rural Development of Shandong Province, Jinan250001, Shandong, China \\ ${ }^{3}$ Shandong Provincial Communications Planning and Design Institute, Jinan250031, Shandong, China \\ ${ }^{4}$ Shandong Taishan Puhui Construction Co. Ltd., Taian271000, Shandong, China \\ ${ }^{5}$ School of Pharmaceutical Sciences, Taishan Medical University, Taian271000, Shandong, China \\ crossref http://dx.doi.org/10.5755/j01.ms.23.4.17049
}

Received 29 November 2016; accepted 05 March 2017

\begin{abstract}
In order to investigate the corrosive resistance of partially steel fiber reinforced concrete (PSFRC), the flexural toughness experiment of nine specimens subjected to corrosion by alternating wet and dry cycles in a simulated marine environment were conducted, which aims at investigating the influence of corrosion time, steel fiber volume fraction and SFRC thickness on PSFRC toughness. The experimental results show that both the mechanical performance and ductile characteristics of PSFRC get worse due to corrosion even if increasing the steel fiber volume. Additionally, the influence of steel fiber content on the toughness and ultimate load are greater than that of PSFRC thickness $(t)$. The increase of $56.6 \%$ and $171 \%$ may be obtained to the mean ultimate load and $I_{10}$ with the increase of steel fiber volume from $0.5 \%$ to $2.0 \%$. This paper could offer a reference to the application of PSFRC in sea-water environment.

Keyword: PSFRC, crack, corrosion, residual strength factor, load-deflection curve.
\end{abstract}

\section{INTRODUCTION}

The main disadvantages of concrete are its low tensile strength and brittleness, but the mixture of randomly distributed short steel fibres in concrete may improve such defect of concrete due to the randomly distributed steel fibres act as crack arrestors in cementations matrices [1-4]. The toughness of steel fibre reinforced concrete (SFRC) is often termed as energy absorption capability when the steel fibres are pulled out for frictional work, so the addition of steel fibres to concrete produce a significant improvement on energy absorption capability [5-7]. Moreover, the toughness is extremely important for the safety and durability of RC structure, and the most common method of toughness testing of fibre reinforced concrete is flexural toughness testing [8-10].

In order to reduce the cost of projects, the appropriate reinforced concrete areas of the addition of steel fibres are the parts requiring high flexural toughness such as concrete tension zone. This kind of SFRC is named partially steel fibre reinforced concrete (PSFRC) in this paper [11].

In this project, nine testing specimens with PSFRC were subjected to corrosion by alternating wet and dry cycles in a simulated marine environment, and flexural toughness experimental investigations considering corrosion were carried out. Based on flexural toughness experiment, the effects of volume fraction $\left(F_{\mathrm{v}}\right)$, SFRC thickness $(t)$ and corrosion time $\left(T_{\text {cor }}\right)$ on the flexural toughness were analyzed, and by the load-deflection curves obtained from experiment, the flexural toughness indexes were calculated and analyzed according to

\footnotetext{
${ }^{*}$ Corresponding author. Tel.: +86-0531-82765943.

E-mail address: gaofenglike@sina.com (F. Gao)
}

CECS13:2009 used for steel fibre reinforced concrete in China [12].

\section{SETUP OF EXPERIMENTAL PROGRAM}

\subsection{Testing program}

The experimental program includes corrosion testing and toughness testing. C30 was concrete class used in all of specimens, and experiment procedure consisted of two stages: (1) tests on standard $100 \times 100 \times 400 \mathrm{~mm}$ dimensions' prisms for corrosion of plain and partially steel fibre reinforced concrete. (2) four-point bending experiments on the specimens for toughness according to the code CECS 13:2009[12].

\subsection{Materials and mixes}

The dimension of the specimen is $100 \times 100 \times 400 \mathrm{~mm}$ in height, width and length, respectively. The micro fibres are mainly used to reduce the tensile cracks as concrete subjected to bending. Therefore, macro fibres have been added into the tension zone of specimens and SFRC thickness is expressed by symbol $t$ as shown in Fig 1a. The materials used for all the concrete mixes are: Portland Cement $42.5 \mathrm{~N}$, natural sand and $20 \pm 5 \mathrm{~mm}$ gravel. The arcade steel fibres with lengths of $45 \mathrm{~mm}$ were used (Fig. $1 \mathrm{~b}$ ). Tap water was used for all the concrete mixes. The mixes used were: $300 \mathrm{~kg} / \mathrm{m}^{3}$ of Portland cement, $768 \mathrm{~kg} / \mathrm{m}^{3}$ of sand, $1152 \mathrm{~kg} / \mathrm{m}^{3}$ of gavel and $180 \mathrm{~kg} / \mathrm{m}^{3}$ of water. The total water-cement ratio was 0.60 . The volume fractions of steel fibre in concrete were $0.5 \%, 1.25 \%, 2.0 \%$ and the mixes were $39 \mathrm{~kg}, 97.5 \mathrm{~kg}$, and $156 \mathrm{~kg}$, respectively. The additions of steel fibers were shown in Fig. 1 c. The aggregate has been previously oven 
dried. All mixes had $1.5 \%$ of super plasticizer by weight of cement.
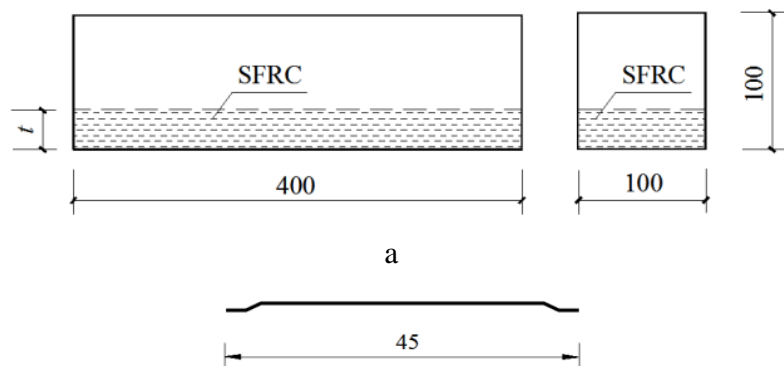

b

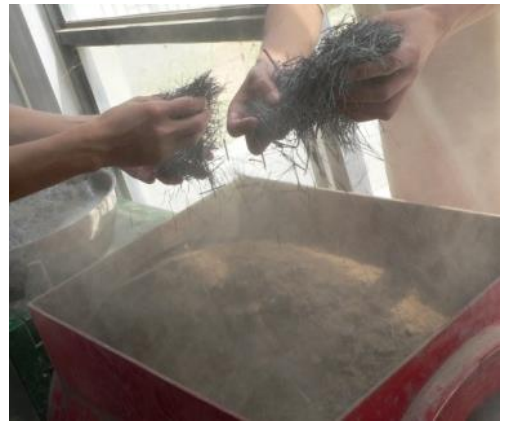

c

Fig. 1. The material and mix of specimen: a-the details of specimens; $b$-arcuate steel fibers; $c$-addition of steel fibers

\subsection{Corrosion test}

The specimens were subjected to corrosion by alternating wet and dry cycles in a simulated marine environment. The concentration of $\mathrm{NaCl}$ in seawater according to the Huanghai Sea [13], which is one of the four key seas of China, were approximately $3 \%$. To accelerate the corrosion of concrete, $\mathrm{NaCl}$ solution with concentration of $7 \%$ was used as etching solution. For the all surrounding of structure members were often subjected to corrosion in practical engineering, the etching methods of spraying specimens with $\mathrm{NaCl}$ solution were adopted as shown in Fig. 2 a and b. After 28-day curing, all specimens were sprayed with $\mathrm{NaCl}$ solution for 12 hours (Fig. 2 b) and air-dried for 12 hours (Fig. 2 a) every day. The duration of dry-wet circulation lasted for $0,1.5$ and 3 months, respectively. The specimens were cleaned up and dried naturally when the circulation ended. Corrosion programme were shown in Table 1.

Subjected to 45 and 90 cycles of the corrosion test, there were no phenomenon of concrete stripping on specimen surface but rust traces appeared in steel fibres concrete outer surface due to the generation of $\mathrm{Fe}(\mathrm{OH})_{3}$ by the corrosion to steel fibres as shown in Fig. 2 c. The distinct corrosion traces could be seen along the steel fibres in the concrete surface of specimen and the slight flow traces of $\mathrm{Fe}(\mathrm{OH})_{3}$ appeared in some of the concrete surface pores as shown in Fig. $2 \mathrm{c}$.

\subsection{Flexural toughness test method}

Specimens were loaded in a four-point loading configuration with two supports spaced a distance of
$300 \mathrm{~mm}$ and two top loading points spaced at $100 \mathrm{~mm}$ on the basis of the procedures required by the code CECS13:2009[12]. Also the evaluation of toughness test results was made as specified in CECS 13:2009[12]. The tests were conducted on a testing machine having the capacity of $200 \mathrm{kN}$ and the rate of loading was $0.1 \mathrm{kN} / \mathrm{min}$.

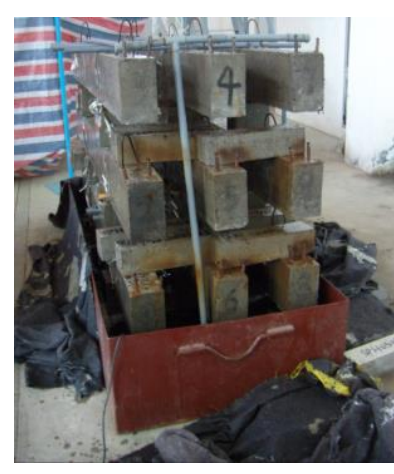

a

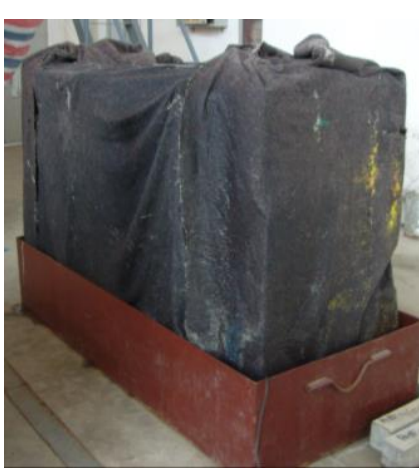

b

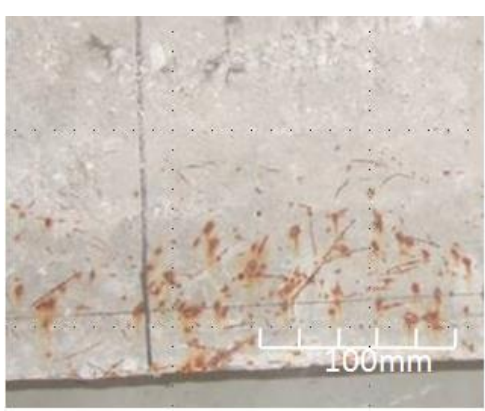

Fig. 2. Corrosion test: $\mathrm{a}$-air-dry; $\mathrm{b}-\mathrm{NaCl}$ solution spray; $\mathrm{c}-\mathrm{Fe}(\mathrm{OH})_{3}$ generation

The mid-span deflection $(\delta)$ was measured using an elastic wire resistance type displacement meter (LVDT) fixed on the bottom surface of the specimen as shown in Fig. 3. During the course of testing, the loading was kept continual and consistent till the specimen failure, and the curves between the vertical load and the mid-span deflection (load- $\delta$ ) were obtained. The designed parameters of specimens such as SFRC thickness $(t)$, steel fiber volume fraction $\left(F_{\mathrm{v}}\right)$ and corrosion time $\left(T_{\text {cor }}\right)$ based on the orthogonal experimental design [14] were listed in Table 1.
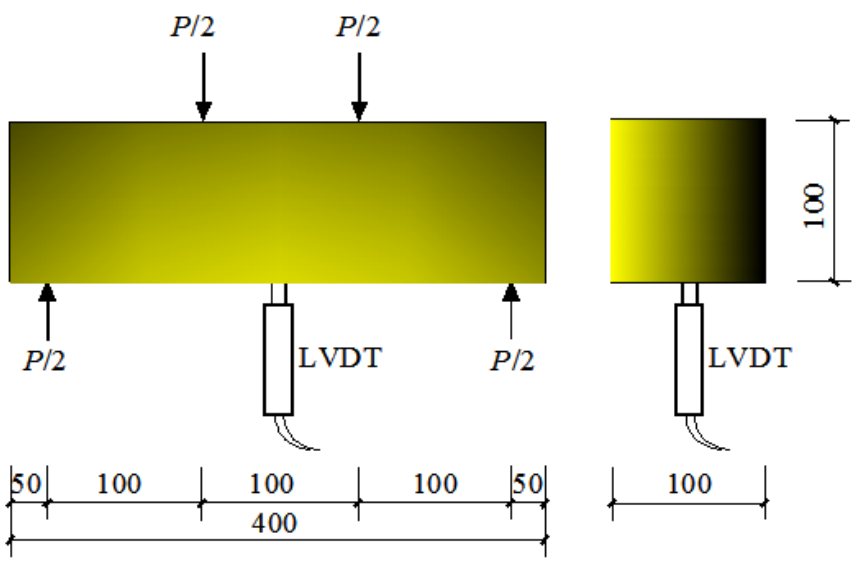

Fig. 3. Bending experiment 


\section{EXPERIMENTAL RESULTS}

\subsection{Failure model}

It could be found from test that due to low ductility, the plain concrete failed once the cracking strength was reached, but the addition of steel fibres in concrete showed excellent crack arresting performance as the specimens were not broken into two pieces at failure stage.

Table 1. Parameters of specimens

\begin{tabular}{|c|c|c|c|}
\hline $\begin{array}{c}\text { Test } \\
\text { specimen }\end{array}$ & $\begin{array}{c}\text { SFRC } \\
\text { thickness } \\
t, \mathrm{~mm}\end{array}$ & $\begin{array}{l}\text { Fiber volume } \\
\text { fraction } F_{\mathrm{v}}, \%\end{array}$ & $\begin{array}{l}\text { Corrosion time } \\
T_{\text {cor }}, \text { month }\end{array}$ \\
\hline S1 & 25 & 0.50 & 0 \\
\hline $\mathrm{S} 2$ & 25 & 1.25 & 1.5 \\
\hline S3 & 25 & 2.00 & 3.0 \\
\hline S4 & 50 & 0.5 & 1.5 \\
\hline S5 & 50 & 1.25 & 3.0 \\
\hline S6 & 50 & 2.00 & 0 \\
\hline S7 & 100 & 0.50 & 3.0 \\
\hline S8 & 100 & 1.25 & 0 \\
\hline S9 & 100 & 2.00 & 1.5 \\
\hline
\end{tabular}

All PFSRC specimens exhibit flexural failure with creation of one hinge in which rotation was concentrated with ongoing mid-span deflection as shown in Fig. 4 a.

Two fibre failures were found on the failure surface at mid-span cross section of specimen as shown in Fig. 4 b: one took place mostly through steel fibre pullout after progressive fibre-matrix debonding; the other was the rupture of steel fibres after yielding at the fractured section. To corrosive specimens, the almost failures of steel fibber were pullout especially after three months' corrosion due to the corrosive substances $\mathrm{Fe}(\mathrm{OH})_{3}$ appeared on the steel fibre surface which decreased the adhesion between steel fibre and concrete.

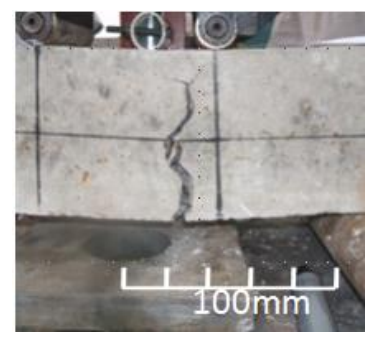

a

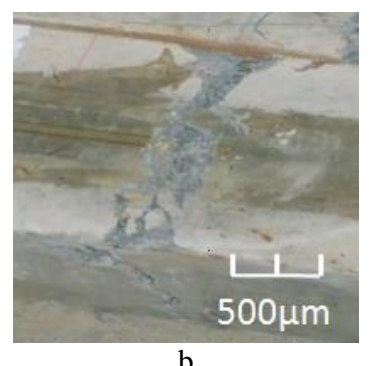

b
Fig. 4. SFRC specimen failure mode: $a$-collapse state; $\mathrm{b}-$ fracture surface

\subsection{Load-deflection relationships}

Load-deflection curves in mid-span for all the specimens are shown in Fig. 5. The black, red, blue curves express $0,1.5$ and 3 months' corrosion time, respectively.
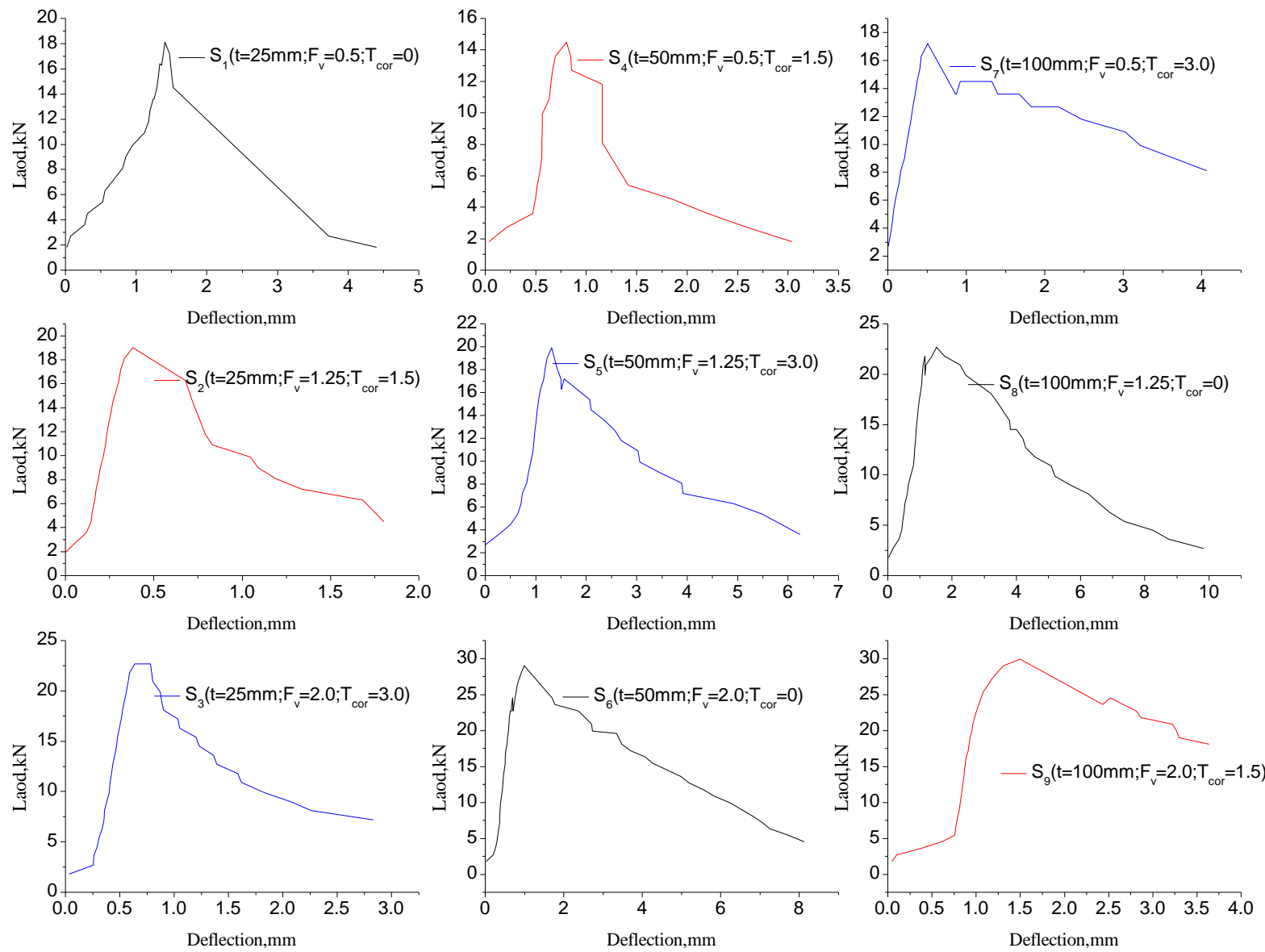

Fig. 5. Load-deflection graphs 
From the above Fig. 5, conclusions may be drawn as following:

1. The descent parts of the curves become steeper with corrosion time increase even if the grow of fibres volume (seen by $S_{1}, S_{2}$ and $S_{3}$ ). This means that the cohesive force between concrete and steel fibres becomes weak for the occurrence of corrosion;

2. The load-deflection curves become plumper and plumper as the steel fibre content grow (seen by $\mathrm{S}_{4}, \mathrm{~S}_{5}$ and $S_{6}$ ), on the contrary, it becomes thinner and thinner (seen by $S_{1}, S_{2}$ and $S_{3}$ ). It suggests that steel fibre content is advantage on the improvement of flexural toughness, but corrosion is disadvantage;

3. The peak vertical load increase with the increase of steel fibre content $\left(F_{\mathrm{v}}\right)$ and SFRC thickness $(t)$. This is because the disordered fibres distributing inside the concrete in three dimensions could form a structural support inside the concrete.

\subsection{Evaluation of flexural toughness indexes}

Flexural toughness is defined as the post-crack energy absorption ability of steel fibre concrete, and the most common measure method is use the load-deflection curve, which can be calculated using the area under the loaddeflection curves based on CECS13:2009 [12]. In CECS13:2009, three indexes $\left(I_{5}, I_{10}, I_{30}\right)$ are used to evaluate the flexural toughness and computed at deflection limits of $\delta, 3 \delta, 5.5 \delta$ and $15.5 \delta$, where $\delta$ denotes the firstcrack deflection (see point A in Fig. 6). The first-crack point $\mathrm{A}$ is determined by setting an overlapping placement between ruler and the linear portion of load-deflection curve according to CECS13:2009. Fig. 6 shows the typical relational curve of the vertical load and the midspan deflection of flexural toughness test and illustrates the calculation of flexural toughness parameters in CECS13:2009[12].

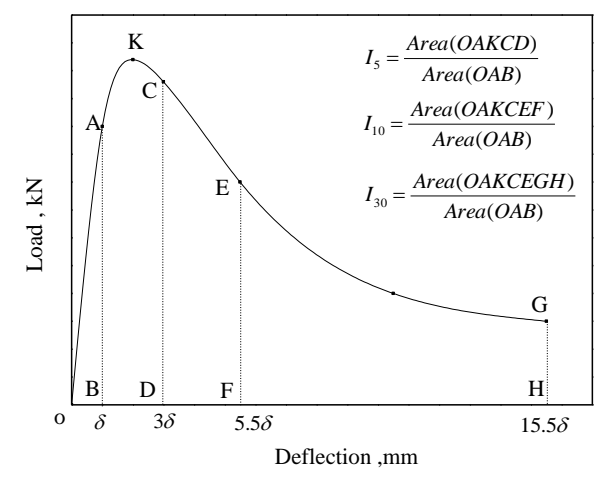

Fig. 6. Toughness definitions
The residual strength factors $R$ could be derived from toughness indexes $I_{5}, I_{10}$ and $I_{30}$, such as residual strength factor $R_{5,10}$ is taken as $\left(I_{10}-I_{5}\right) \times 20$ according to (ASTM: C1018-97) [15]. The results of ultimate load, $\delta, I_{5}$, $I_{10}$ and $R_{5,10}$ for all the load-deflection curves of test specimen are listed in Table 2.

\subsection{Discussion of flexural toughness indexes}

PSFRC toughness indexes change with corrosion time $\left(T_{\text {cor }}\right)$, fibre contents $\left(F_{\mathrm{v}}\right)$, and PSFRC thickness $(t)$. To all of toughness indexes, $I_{10}$ is often adopted for the evaluation of flexural toughness due to the large difference between the load-deflection curves at the relatively large deflection stage. The mean values of each parameter under the same factors are used to reflect the change of PSFRC performance. The symbol $\Omega$ represent ultimate load, $\delta, I_{10}$ and $R_{5,10}$ in Fig. 7, Fig. 8, and Fig. 9, and detailed discussions are given as following.

\subsubsection{Influence of corrosion}

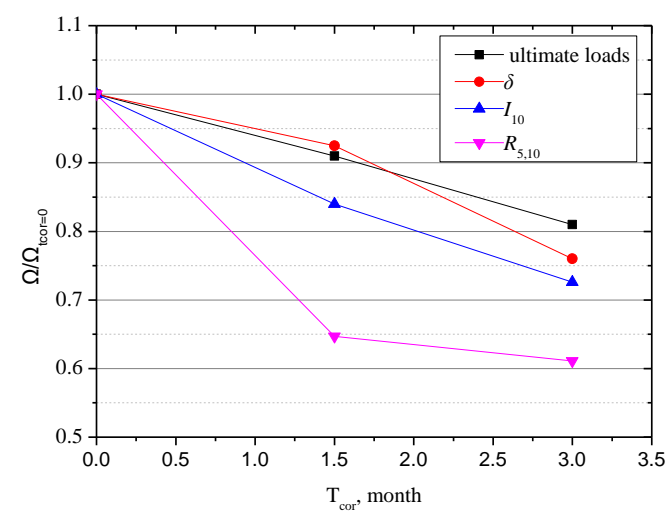

Fig. 7. Effect of corrosion

Fig. 7 shows the variation of parameters with corrosion time increase. It could be seen from Fig. 7: corrosion decreased the deflection and ultimate loads of specimen, such as the deflection of corrosive specimens decreased $9.2 \% \quad\left(T_{\text {cor }}=1.5\right)$ and $19.7 \% \quad\left(T_{\text {cor }}=3.0\right)$ compared to no corrosive specimen $s_{1}$, respectively. It indicates that corrosion decrease the stiffness and carrying capacity of PSFRC specimens. Similarly, the decline trend of $I_{10}$ also inferred that corrosion has disadvantageous influence on PSFRC toughness.

The residual strength $R_{5,10}$ could provide a clearer comparison on the negative effects due to corrosion on decreasing the post-cracking toughness of PSFRC. From Fig. 7 , the decrease of $R_{5,10}$ by $35.3 \%$ and $38.8 \%$ when the corrosion times are 1.5 and 3.0 months, which show that corrosion decrease the post-cracking behaviours and cause to a poor ductility.

Table 2. Toughness test results for specimens calculated using $P-\delta$ curves

\begin{tabular}{|c|c|c|c|c|c|c|c|c|c|}
\hline Specimen & $\mathrm{S}_{1}$ & $\mathrm{~S}_{2}$ & $\mathrm{~S}_{3}$ & $\mathrm{~S}_{4}$ & $\mathrm{~S}_{5}$ & $\mathrm{~S}_{6}$ & $\mathrm{~S}_{7}$ & $\mathrm{~S}_{8}$ & $\mathrm{~S}_{9}$ \\
\hline Ultimate load, $\mathrm{kN}$ & 18.1 & 19 & 19 & 14.5 & 19.9 & 29 & 17.2 & 22.7 & 29.9 \\
\hline$\delta, \mathrm{mm}$ & 0.78 & 0.18 & 0.36 & 0.56 & 0.74 & 0.35 & 0.15 & 0.52 & 0.79 \\
\hline$I_{5}$ & 6.18 & 9.82 & 13.00 & 7.14 & 8.42 & 15.29 & 5.78 & 10.83 & 14.77 \\
\hline$I_{10}$ & 8.95 & 19.3 & 22.84 & 9.79 & 14.66 & 36.26 & 13.44 & 25.93 & 28.05 \\
\hline$R_{5,10}$ & 55.4 & 184.3 & 196.9 & 53.0 & 124.8 & 419.5 & 153.1 & 302.0 & 265.6 \\
\hline
\end{tabular}




\subsubsection{Influence of fiber contents}

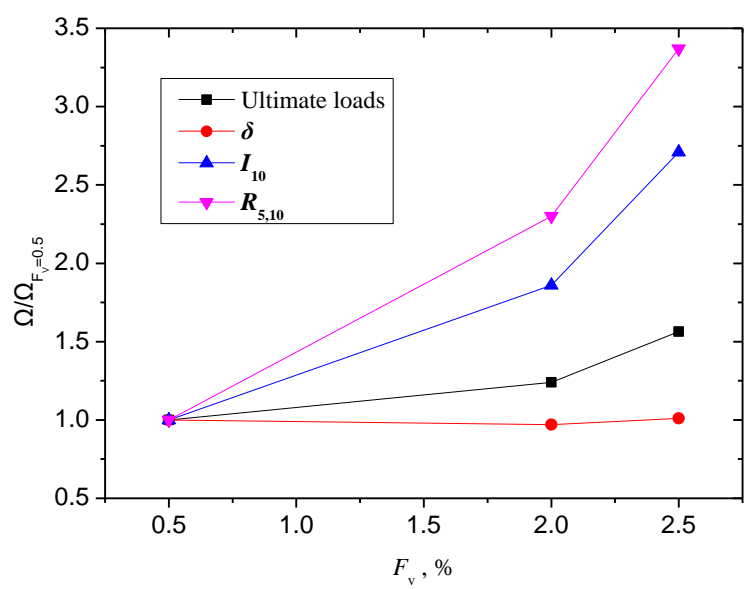

Fig. 8. Effect of fiber contents

The influences of the steel fiber volume fraction on PSFRC are shown in Fig. 8. It can be seen that the addition of fibers in concrete have a significant improving effect on its flexural toughness. Compared with the PSFRC containing $0.5 \%$ steel fiber, ultimate loads are increase by $23.5 \%$ and $56.6 \%$ as $1.25 \%$ and $2.00 \%$ steel fiber content, respectively, and the additions of steel fibers have less effect on the early uncracked stiffness.

Compared with $0.5 \%$ steel fiber content, $I_{10}$ is increase by $86.2 \%$ and $171 \%$ as $1.25 \%$ and $2.0 \%$ steel fibers content, respectively. It can be inferred that the volume fraction plays a major role on the improvement of PSFRC structure ductility. Also, the $R_{5,10}$ of specimens have a high increase with the steel fibers volume increase due to the contribution of steel fibers in improving the post-cracking characteristic.

\subsubsection{Influence of PSFRC thickness}

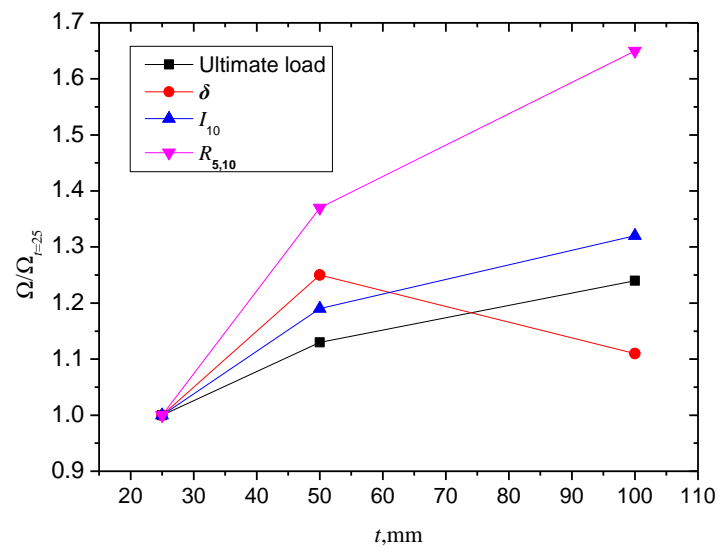

Fig. 9. Effect of PSFRC thickness

The flexural toughness of PSFRC also increase when SFRC thickness increase from $25 \mathrm{~mm}$ to $100 \mathrm{~mm}$ as shown in Fig. 9.

The mean first crack deflection $\delta$ exhibits an irregularly varying trend as to the increase of the SFRC thickness due to SFRC thickness has less effect on the first crack deflection or the measurement error of test may be having a greater impact on test results because of smaller first crack deflection values.
The indices, $I_{10}$ and $R_{5,10}$ show the anticipated trend that a greater thickness of SFRC results in a greater toughness.

\section{DISCUSSION}

To investigate the performance of PSFRC, the toughness indexes $I_{10}$ comparison of PSFRC and SFRC (data from the literature [5]) are shown as the change of steel fiber content in Fig. 10. Compared to literature [5] reported that SFRC $I_{10}$ increased to $145 \%$, which is $186 \%$ in our test, as for the steel fiber content increase from $0.5 \%$ to $2.0 \%$, it can be inferred that the volume fraction has more influence on PSFRC than SFRC. So the increase of steel fiber content is an effective measure to improve the toughness of PSFRC.

Also, in order to investigate the corrosion resistances of PSFRC toughness as contrast with SFRC, comparison with SFRC (data from the literature [16]) are carried out corresponding with corrosive time. Because there are no exact same experimental conditions, the data from literature [16] are used, which $\mathrm{NaCl}$ solution concentration is $5 \%$, closed to the experimental condition of our paper. In literature [16], the indexes $I_{10}$ of SFRC specimens with fiber contents $0.5 \%$ and $1 \%$ reduced to about $9.8 \%$ after 1.0 month corrosion, which is lower than PSFRC.

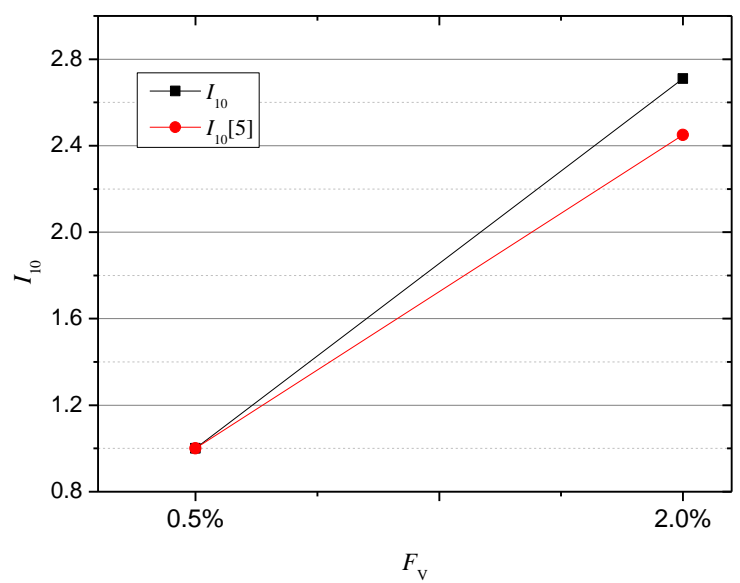

Fig. 10. Comparison of $I_{10}$ to PSFRC than SFRC

It can be inferred that due to corrosion the decrease of PSFRC toughness greater than SFRC.

Through the above comparison, it can be seen that in the reality of engineering practice, only the addition of steel fibers to the parts requiring high flexural toughness performance in the structural member could enhance the strength and flexural toughness of concrete and structural components. Overall, the increase of steel fiber content and SFRC thickness improve the toughness and ultimate load for PSFRC. However, by comparison of the varying of the toughness indices due to the steel fibers content and PSFRC thickness, it can be found that the effect of steel fibers content on the toughness and ultimate load are greater than that of SFRC thickness. In other word, the flexural toughness is supposed to increase mainly owing to the fact that a greater amount of steel fiber exists, which enable a greater capability of resisting the tensile stress and corrosion, especially at the post-cracking stages. So, in the reality of engineering practice, to enhance the strength and 
flexural toughness of PSFRC, the best way is the increase of steel fibers content rather than the SFRC thickness.

\section{CONCLUSIONS}

The following conclusions could be drawn from this study:

1. PSFRC (Only the addition of steel fibers to concrete parts requiring high flexural toughness performance) could significantly enhance the strength and flexural toughness of concrete;

2. All PSFRC specimens exhibit a good ductility and post-crack deformability; the pullout of steel fibre is the main failure to PSFRC specimen subjected to corrosion;

3. Corrosion could reduce the toughness properties of PSFRC structure, and the decrease of PSFRC toughness due to corrosion greater than SFRC, and specimens with steel fibre content of $2.5 \%$ indicated better corrosion resistance compared to the other specimens;

4. Compared to the PSFRC specimens containing $0.5 \%$ steel fibre, the mean ultimate load and $I_{10}$ are increase by $56.6 \%$ and $171 \%$ as $2.0 \%$ steel fibres, respectively. So the best way to enhance the strength and flexural toughness of PSFRC concrete may be the increase of steel fibre content rather than the SFRC thickness.

5. In the reality of engineering practice, PSFRC could enhance the strength and flexural toughness of concrete or structural components, and reduce the cost of projects compared with SFRC.

\section{Acknowledgements}

The authors gratefully acknowledge the financial support from the Development Transportation Science and Technology Project of Shandong Province under Grant No.2015B30 and the Technology Project of Shandong Province Construction Department of Urban and Rural Housing of China under Grant No. 2016KY027.

\section{REFERENCES}

1. Federica, G., Giuseppe, T., Giovanni, P. Post-peak Fatigue Performance of Steel Fiber Reinforced Concrete under Flexure Materials and Structures 49 (10) 2016: pp. 4229-4245. https://doi.org/10.1617/s11527-015-0783-3

2. Tee, S.C., Oh, J.H., Cho, J.Y. Fiber Efficiency in SFRC Members Subjected to Uniaxial Tension Construction and Building Materials 113 (15) 2016: pp. 479-487.
3. Ali, A.A., Sharifah, M.S.M., Demetrios, M.C. A Simplified Finite Element Model for Assessing Steel Fiber Reinforced Concrete Structural Performance Computers \& Structures 173 (9) 2016: pp. 37-49.

4. Tadepalli, P.R., Mo, Y.L. Mechanical Properties of Steel Fiber Concrete Magazine of Concrete. Research. 65 (8) 2013: pp. $462-474$.

5. Song, P.S., Hwang, S. Mechanical Properties of HighStrength Steel Fiber-reinforced Concrete Construction and Building Materials 18 (9) 2004: pp. 669-673. https://doi.org/10.1016/j.conbuildmat.2004.04.027

6. Mo, K.H., Yap, K.K.Q., Alengaram, U.J. The Effect of Steel Fibers on The Enhancement of Flexural and Compressive Toughness and Fracture Characteristics of Oil Palm Shell Concrete Construction and Building Materials 55 (3) 2014: pp. 20-28.

7. Zhang. P., Zhao, Y.N., Li, Q.F. Flexural Toughness of Steel Fiber Reinforced High Performance Concrete Containing Nano-SiO2 and Fly Ash The Scientific World Journal 1 (9) 2014: pp. 56-66.

8. Holschemacher, K., Mueller, T., Ribakov, Y. Effect of Steel Fibers on Mechanical Properties of High-strength Concrete Materials \& Design 31 (5) 2010: pp. 26042615.

9. Toledo, R.D., Koendersm, E.A.B., $\quad$ Formagini, S., Fairbairn, E.M.R. Performance Assessment of Ultra High Performance Fiber Reinforced Cementitious Composites in View of Sustainability Materials \& Design 36 (4) 2012: pp. 880-888.

10. Kim, D.J., Park, S.H., Ryu, G.S., Koh, K.T. Comparative Flexural Behavior of Hybrid Ultra High Performance Fiber Reinforced Concrete with Different Macro Fibers Construction and Building Materials 25 (11) 2011: pp. 4144-4155.

11. Zhang, J., Henrik, S. Fatigue Performance in Flexure of Fiber-reinforced Concrete ACI Materials Journal 95 (1) 1998: pp. 58-67.

12. China Construction Association standard. Standard Test Methods for Fiber Reinforced Concrete. CECS13:1989; China Planning Press: Beijing, China, 1990. (In Chinese)

13. Ge, A. Research on The Corroding Characteristic of Reinforced Concrete in Seawater (M.S. thesis) China Ocean University, Shandong, China. 2004.

14. Fang, K.T., Ma, CX. Orthogonal and Uniform Experimental Design. Beijing: Science Press. 2001 (in Chinese)

15. ASTM C1018-97. "Standard Test Method for Flexural Toughness and First-crack Strength of Fiber-reinforced Concrete (Using Beam with Third-point Loading)," Annual Book of ASTM Standards, 1997.

16. Wang, M. Corrosion and Protection of Steel Fiber Reinforced Concrete, $\mathrm{PhD}$ thesis. Jiangsu: Soochow University, 2011. 